\title{
ORIGINAL ARTICLE \\ Clinical characteristics and surgical outcome of thoracic myelopathy caused by ossification of the ligamentum flavum: a retrospective analysis of 85 cases
}

\author{
$\mathrm{Z} \mathrm{Li}{ }^{1,2,4}, \mathrm{D} \mathrm{Ren}^{1,4}$, Y Zhao ${ }^{1,4}, \mathrm{~S} \mathrm{Hou}{ }^{1}, \mathrm{~L} \mathrm{Li}^{1}, \mathrm{~S} \mathrm{Yu}{ }^{3}$ and $\mathrm{T} \mathrm{Hou}^{3}$
}

\begin{abstract}
Study design: A retrospective comparative study.
Objectives: To describe the clinical features and radiological findings, to assess the safety and effectiveness of posterior decompressive laminectomy and resection of the ossification of the ligamentum flavum (OLF), and to determine which presurgical and surgical variables were most closely related to postsurgical prognosis of thoracic myelopathy (TM) caused by OLF in China.

Methods: Eighty-five patients with the diagnosis of TM caused by OLF received surgical treatment from July 1998 to May 2012. Clinical data were collected from medical and operative records. Correlations between the surgical outcome and various factors were also analyzed.

Results: All cases were followed up for a mean of 49.2 months (range, 24-190 months) postoperatively. The mean Japanese Orthopaedic Association score was 3.8 points preoperatively and 8.2 points at the final follow-up, yielding a mean recovery rate of $63.0 \%$. Postoperative complications included transient neurological deficits (9 cases), persistent neurological deficits (4 cases), dural tears (17 cases), cerebrospinal fluid leakage (9 cases), wound dehiscence $(2$ cases) and wound infection (3 cases). The OLF level (middle thoracic), preoperative duration of symptoms, intramedullary signal change on $\mathrm{T} 2 \mathrm{WI}$ and preoperative severity of myelopathy were important predictors of surgical outcome.

Conclusions: Biomechanical and anatomical factors may have a key role in thoracic OLF progression. Posterior decompressive laminectomy and resection of the OLF can be considered an effective, reliable and safe alternative procedure. The OLF level, preoperative duration of symptoms, intramedullary signal change on T2WI and preoperative severity of myelopathy were confirmed and significantly correlated with the surgical outcome.
\end{abstract}

Spinal Cord (2016) 54, 188-196; doi:10.1038/sc.2015.139; published online 4 August 2015

\section{INTRODUCTION}

Thoracic myelopathy (TM) is a relatively rare spinal disorder secondary to several degenerative spinal disorders, including intervertebral disc herniation, posterior spurs, ossification of posterior longitudinal ligament and ossification of the ligamentum flavum (OLF). ${ }^{1-9}$ With the increasing use of diagnostic tools, such as computed tomography $(\mathrm{CT})$ and magnetic resonance imaging (MRI), OLF is gradually being recognized as a major cause of acquired thoracic spinal canal stenosis. The ligamentum flavum is a connective tissue that is attached to the posterior side of the caudal lamina and the anterior side of the rostrally adjacent lamina. The ligamentum flavum extends laterally from the midline to the intervertebral foramen forming the superior-posterior boundary of the foramen. It then turns dorsally outside the foramen to fuse with the capsule of the articular facets. ${ }^{10,11}$ The normal ligament is highly elastic, based on the large proportion of elastic fibers, accounting for $60-70 \%$ of the dry weight, with little blood flow. Functionally, the ligamentum flavum provides a static, elastic force to support the spinal column in its return to a neutral position after flexion and extension movements. Thus, when the ligamentum flavum is replaced by a mature bone, its osseous morphology should be V-shaped or a part of V shape on CT images. ${ }^{12}$

Although thoracic OLF has been reported in several Asian countries, such as Japan, ${ }^{11-14}$ China $^{3,4,15-19}$ and South Korea, ${ }^{20-22}$ and also in Caucasian and Caribbean ethnic groups, ${ }^{23-28}$ extensive studies on thoracic OLF including a large number of patients have not yet been reported in the literature. This is partly due to the relatively low mean prevalence of thoracic OLF, which was reported as 3.8\% in China and as $6.2 \%$ for Japanese men and $4.8 \%$ for Japanese women. ${ }^{11,17}$ Once the thoracic OLF is symptomatic, it is usually progressive and refractory to conservative treatment, and surgical decompression is indicated. The most common mode of treatment is posterior decompression by laminectomy. However, the surgical outcomes vary. ${ }^{29-32}$ Because obtaining detailed data and analysis from a single center study on this topic has been insufficient and difficult, we conducted a study on a large number of patients with TM caused

${ }^{1}$ Department of Orthopaedics, First Affiliated Hospital of PLA General Hospital, Beijing, People's Republic of China; ${ }^{2}$ Department of Orthopaedics, the 210 Hospital of Chinese PLA, Dalian, Liaoning Province, People's Republic of China and ${ }^{3}$ Department of Orthopedics, Tenth People's Hospital of TongJi University, Shanghai, People's Republic of China ${ }^{4}$ These authors contributed equally to this work.

Correspondence: Professor Z Li, Professor Y Zhao or Dr S Hou, Department of Orthopedics, First Affiliated Hospital of PLA General Hospital, No.51, Fucheng Rd, Beijing 100048, People's Republic of China.

E-mail: lizhonghaispine@126.com, userzy@@qq.com or Ivshunman@126.com

Received 2 February 2015; revised 24 June 2015; accepted 3 July 2015; published online 4 August 2015 
by OLF; we analyzed their preoperative and postoperative symptoms, radiological findings, and intraoperative findings. The aim of this retrospective multicenter study was to describe the clinical features and radiological findings, to assess the safety and effectiveness of laminectomy, and to determine the prognostic factors relevant for patients with TM caused by OLF in China.

\section{MATERIALS AND METHODS}

\section{Patient population}

This is a retrospective clinical study. From July 1998 to May 2012, 96 patients having thoracic OLF-induced myelopathy at three institutes (First Affiliated Hospital of PLA General Hospital, First Affiliated Hospital of PLA Second Military Medical University and Tenth Affiliated Hospital of Tongji Medical University) were included and who were then observed for a minimum of 2 years postoperatively. Criteria supporting a diagnosis of TM caused by OLF were based on findings of clinical, radiologic and pathologic evaluations. Clinical evaluation was based on history and physical examination. Typical clinical symptoms and findings included numbness and sensory deficits in the lower limbs and below the relative level of the trunk, weakness in the lower extremities accompanied by difficulty in walking and sphincter dysfunction. Positive physical examinations included increased lower limb muscle tension and deep tendon and pathological reflexes.

MRI and three-dimensional CT were performed in every patient. The radiologic work-up provided the characteristics of OLF (that is, location, number of affected segments, axial and sagittal configuration), and showed possible spinal cord involvement. The new categorization of the axial configuration of OLF is by unilateral, bilateral and bridged type (Figure 1), and the categorization of the sagittal configuration of OLF is by beak type and round type (Figure 2) according to previous reports with some modifications. ${ }^{33,34}$

To evaluate the effect of the thoracic OLF purely, OLF should be apparent and the direct cause of myelopathy. Patients were excluded on the basis of the following criteria: diagnosis of OLF occurring with concurrent ventral compressive lesion, such as thoracic disc herniation or ossification of posterior longitudinal ligament at the same level or cervical compressive myelopathy such as ossification of posterior longitudinal ligament or cervical spondylosis; receipt of surgery using an anterior approach or circumferential spinal cord decompression through a posterior approach; history of spinal tumor; or previous spinal surgery. In this study, $11(11.5 \%)$ were lost to follow-up. The remaining $85(88.5 \%)$ patients who could be followed up regularly comprised the patient cohort of this study, and their records were reviewed. Various factors that could affect surgical outcome were examined: age at surgery, sex, body mass index, current smoking, alcohol, diabetes mellitus, preoperative duration of symptoms, preoperative severity of myelopathy, intramedullary signal change on T2-weighted MRI, configurations of OLF in axial (unilateral, bilateral or bridged) and sagittal (beak or round) plane, number of levels involved, and dural ossification (DO) (Table 1).

\section{Surgical technique}

Posterior decompressive laminectomy and resection of the OLF at the involved levels were performed in all patients by highly experienced spine surgeons. Intraoperative somatosensory-evoked potentials were routinely used to observe spinal cord activity in all patients. Briefly, the patient was placed in a prone position and the posterior elements of the spine were exposed through a midline incision at the site of the lesion. After the necessary dissection, the spinous processes were resected during the operation, and laminectomies were performed by using rongeurs and a high-speed drill. The decompression covered at least one level above and below the area affected by the OLF. The width of the laminectomy was approximately one-third to one-half portion of the facet joint and could extend when ossification of the facet joint capsules occurred. The ossified lesions were carefully resected microscopically by use of a diamond drill or a small-angled punch rongeur. The OLF was detached on all sides, made free floating and elevated from the dura. Venous plexus bleeding was noted from the lateral gutters during decompression. Electrocautery, gelatin sponge strips and neuropatties were used to achieve hemostasis.

The dura mater usually adhered to the OLF and sometimes also ossified. In cases like this, we excised both the outer layer of the dura and the OLF with sharp dissection, leaving the inner dural layer intact. Some of the very small dural tears were covered only with gelatin sponge and did not receive suturing. Some patients had the defect repaired immediately with absorbable gelatin sponge, and with either muscle/fascia, artificial dura, or fibrin glue. The muscle/fascia was flattened with a mallet and placed over the dural defect to completely cover the defect. Two pieces of gelatin sponge were then layered over it. In cases when artificial dura was used, the material was cut into the appropriate size and shape and then placed over the dural defect. In cases when fibrin glue was used, the material was sprayed directly onto the dura mater and gelatin sponge was then layered over it.

Posterior fusion and instrumentation was also implemented mainly in the cervicothoracic junction and thoracolumbar junction, with the use of transpedicular screws and longitudinal rods to maintain normal spinal alignment and restore spinal stability. After the spinal cord was decompressed, the paravertebral muscle and the supraspinous ligament were sutured. All patients were required to stay in bed for 3 days after surgery, and they were encouraged to walk assisted by a thoracolumbar orthotic brace for an average of 8 weeks postoperatively.

\section{Postoperative observation and follow-up}

The follow-up examinations were scheduled at 3 months, 6 months and 1 year after surgery, and every half year beyond the first year after surgery. Operative time, intraoperative blood loss and complications were reviewed from the medical records. All patients were seen in follow-up visits, during which the neurologic outcomes were evaluated according to the Japanese Orthopaedic Association (JOA) scoring system for cervical myelopathy, excluding scores for the upper extremities (full score, 11 points) (Table 2), before and after surgery. Postoperative recovery rate $(\mathrm{RR})$ was calculated as: $\mathrm{RR}=$ (postoperative-preoperative JOA score $) /(11$-preoperative JOA score $) \times 100 \%$. The RR was then used to define the surgical outcome: excellent $(R R \geqslant 75 \%)$, good $(75 \%>R R \geqslant 50 \%)$, fair $(50 \%>R R \geqslant 25 \%)$, unchanged $(24 \%>R R \geqslant 0 \%)$ and deteriorated $(\mathrm{RR}<0 \%)^{35}$
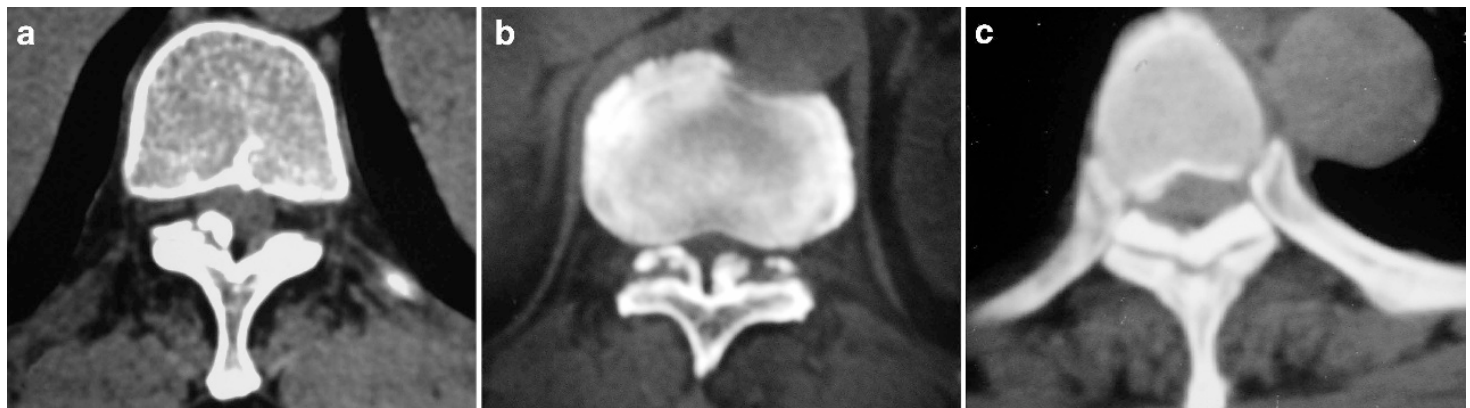

Figure 1 Axial configuration of thoracic OLF was classified into three subgroups: unilateral (a), bilateral (b) and bridged (c) types on schematic drawings and axial CT scan. 

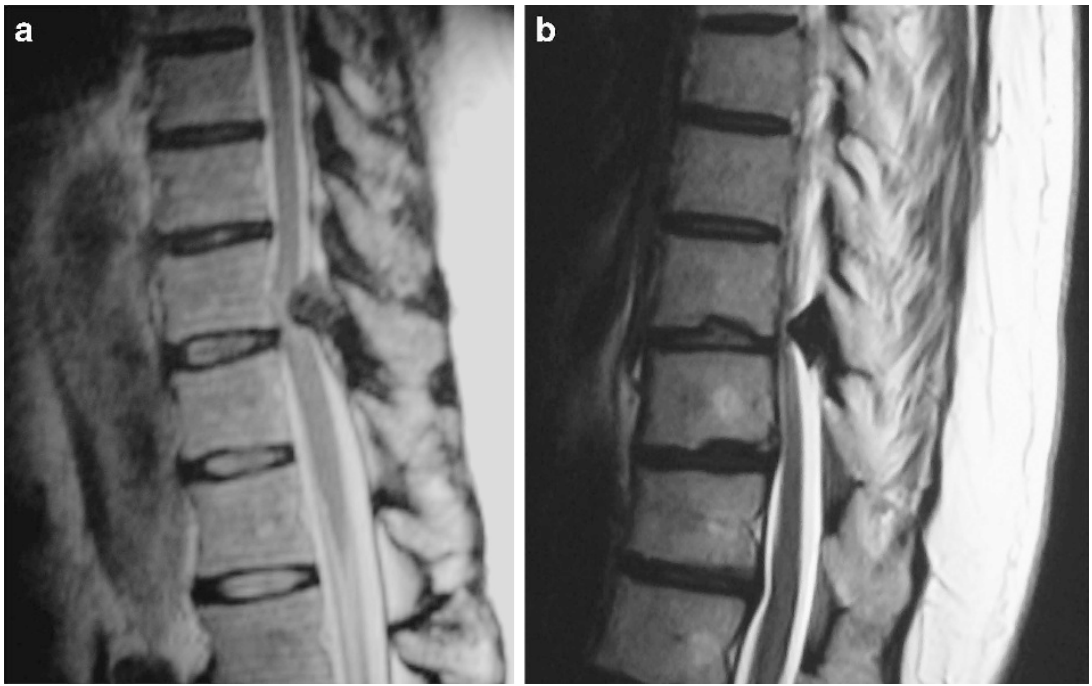

Figure 2 Sagittal configuration of thoracic OLF was classified into two subgroups: round (a) and beak (b) types on schematic drawings and T2-weighted sagittal MRI/sagittal CT scan.

Table 1 Summary of demographic data and perioperative parameters in 85 patients with thoracic OLF

\begin{tabular}{lc}
\hline Variable & Observed value \\
\hline Age at surgery, years, mean (range) & $60.2(40-78)$ \\
Sex (male/female) & $54 / 31$ \\
BMI, kg m ${ }^{-2}$, mean (range) & $23.7(17.1-33.6)$ \\
Current smoking, number (\%) & $19(22.4)$ \\
Alcohol, number (\%) & $13(15.3)$ \\
Diabetes mellitus, number (\%) & $9(10.6)$ \\
Preoperative duration of symptoms, months, mean (range) & $13.5(1-32)$ \\
Preoperative JOA score, mean (range) & $3.8(1-9)$ \\
JOA scores at final follow-up, mean (range) & $8.2(3-11)$ \\
Postoperative improvement rate, \%, mean (range) & $63.0(0-100)$ \\
Hospital stay, days, mean, (range) & $16.4(11-32)$ \\
Follow-up period, months, mean (range) & $49.2(24-190)$ \\
Operation time, minutes, mean (range) & $143.5(70-425)$ \\
Blood loss, ml, mean (range) & $495.3(120-1,890)$ \\
\hline
\end{tabular}

Abbreviations: BMI, body mass index; JOA, Japanese Orthopaedic Association; OLF, ossification of the ligamentum flavum.

\section{Statistical analyses}

The Statistical Package for Social Sciences software for Windows (Ver. 17.0, SPSS Inc, Chicago, IL, USA) was used for the analysis. The chi-square test was used to compare the categorical variables between two and three groups. Student's $t$-tests and one-way analysis of variance were used to compare the statistical significance of the association for continuous data. Pearson's and Spearman's rank correlation coefficients were used to test the correlations between various factors and RR. Multiple regression analysis was performed to identify the independent factors associated with RR. Results are expressed as the mean \pm standard deviation, with a $P$ value of $<0.05$ considered statistically significant.

\section{RESULTS}

Clinical characteristics and surgical outcome

The study group consisted of 31 female and 54 male patients between 40 and 78 years of age, averaging an age of 60.2 years. The average disease duration from onset to surgery was 13.5 months (range, 1-32 months). Twenty-two patients had lesions located in the upper
Table 2 Japanese orthopaedic association (JOA) scoring system modified for thoracic myelopathy

\begin{tabular}{lc} 
Neurological status & Score (points) \\
\hline A. Motor dysfunction of lower limbs & \\
Unable to walk & 0 \\
Able to walk on flat floor with walking aid & 1 \\
Able to walk up and/or down stairs with handrail & 2 \\
Lack of stability and smooth reciprocation of gait & 3 \\
Normal & 4 \\
& \\
B. Sensory deficit in lower limbs & \\
Severe sensory loss or pain & 0 \\
Mild sensory loss & 1 \\
Normal & 2 \\
& \\
C. Sensory deficit in trunk & \\
Severe sensory loss or pain & 0 \\
Mild sensory loss & 1 \\
Normal & 2 \\
& \\
D. Sphincter dysfunction & \\
Unable to void & \\
Marked difficulty in micturition & \\
Mild difficulty in micturition & \\
Normal & 1 \\
\hline
\end{tabular}

thoracic spine (T1-T4), 19 patients in the middle thoracic spine (T5-T9) and 44 patients in the lower thoracic spine (T10-T12). DO occurred in 21 cases, and the incidence was $24.7 \%$. Intramedullary signal change on T2-weighted MRI was shown in 18 patients (Figure 3). The average operative time was $143.5 \mathrm{~min}$ (range, 70-425 min). The average blood loss was $495.3 \mathrm{ml}$ (range, 120-1890 ml). No patient received a blood transfusion. All cases were followed up for a mean of 49.2 months (range, 24-190 months) postoperatively. All patients received posterior decompressive laminectomy (Figure 4). Posterior laminectomy combined with lateral fusion with instrumentation was performed in 28 patients (32.9\%). The mean JOA score was 3.8 points preoperatively, and 8.2 points at the final follow-up, yielding 
a mean RR of $63.0 \%$. Thus, a statistically significant improvement in the JOA score was obtained at the final follow-up examination $(P<0.05)$. No improvement or symptom aggravation was found in 4 patients $(4.7 \%)$, and a RR of more than $50 \%$ was observed in 63 patients $(74.1 \%)$.

\section{Complications}

Transient deterioration of TM occurred immediately after the surgery in nine patients $(10.6 \%)$. After dehydration and corticosteroid therapy,

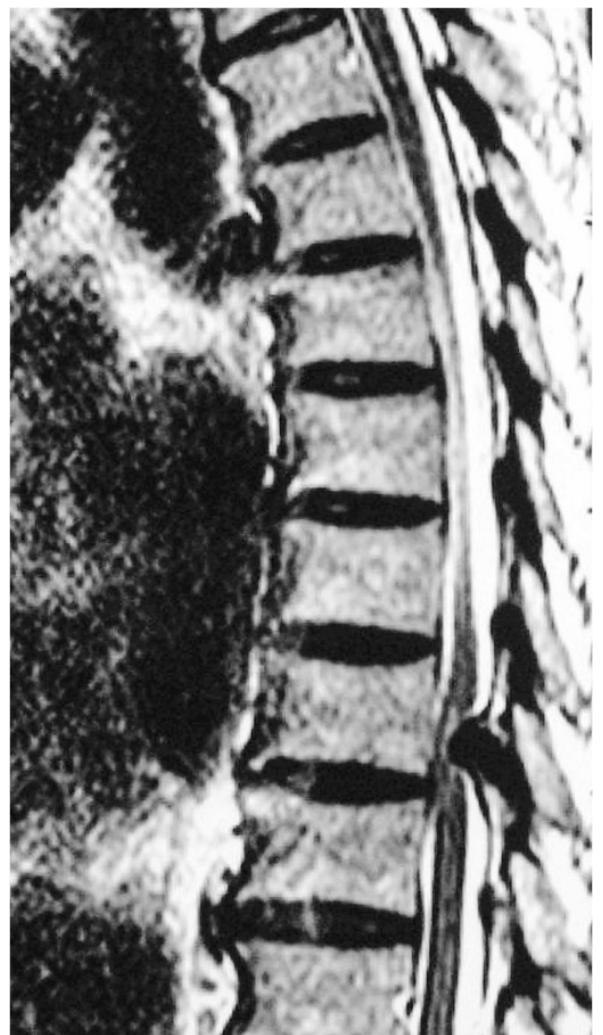

Figure 3 Round type of OLF on T2-weighted MRI shows hypointense signal. all of them recovered spontaneously and improved beyond their preoperative condition during in-hospital course or until clinical follow-up 3-6 months postoperatively in all patients. There were four patients who suffered from late postoperative neurologic deterioration or persistent aggravation of paralysis. Potential etiologies include ischemia-reperfusion injury, microthrombi and altered perfusion due to internal recoil of spinal cord architecture following decompression.

Of the 85 patients, 17 had dural tears in the operation period, yielding an overall incidence of $20.0 \%$. Cerebrospinal fluid (CSF) leakage occurred in 9 of 17 patients (52.9\%). Leakage of CSF did not result in any neurologic degradation but was associated with patient discomfort, which improved gradually within the first postoperative month. These patients were kept in the prone or lateral position in bed for about 2-3 days after operation. The color and volume of drainage fluid were recorded. When the drainage had reduced to less than $50 \mathrm{ml}$ per $24 \mathrm{~h}$, the subfascial drain was removed. CSF leakage stopped after 5-7 days in all nine cases. Two patients developed CSF pseudocyst during the follow-up, both of which were cured by repeated ultrasound-guided puncture and aspiration.

There were two patients who experienced wound dehiscence, making for an incidence of $2.4 \%$. Both of them were cured by a debridement procedure performed under anesthesia. Three cases (3.5\%) developed postoperative wound infections that resolved after a single surgical irrigation and debridement, primary closure, and intravenous antibiotics for 2-3 weeks. No thoracic kyphosis was seen at the final follow-up. No instrumentation-related complication was observed in any patient during the entire follow-up period.

\section{Various factors associated with surgical outcomes}

Univariate analysis revealed that sex, body mass index, current smoking, alcohol, diabetes mellitus, number of levels involved, sagittal configurations of OLF, DO and aided by fusion with instrumentation were not significantly related to the surgical outcome $(P>0.05$, Table 3). The RR at the final follow-up correlated significantly with age at surgery, preoperative duration of symptoms, the OLF level, axial configurations of OLF, intramedullary signal change on T2WI and preoperative severity of myelopathy $(P<0.05)$. Furthermore, multiple
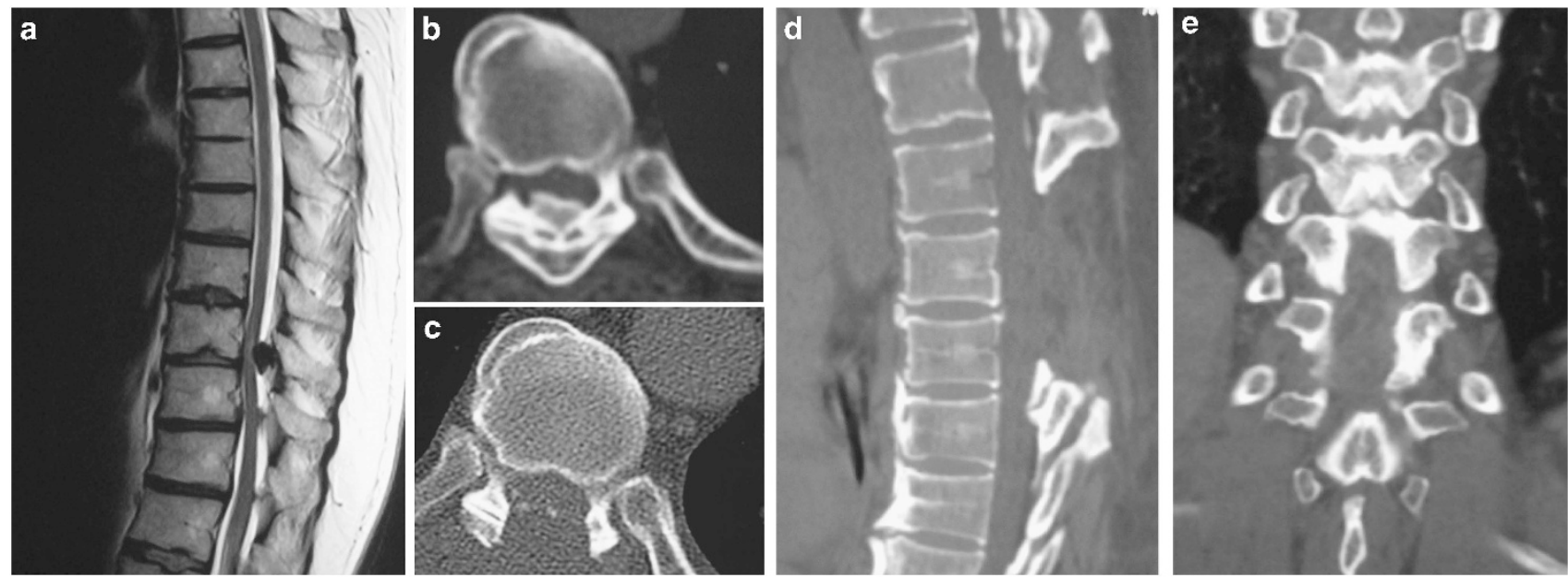

Figure 4 A 65-year-old male was diagnosed as having TM caused by OLF in T9-T10. Posterior decompressive laminectomy and resection of the OLF without surgery related-complications was performed on the patient. After operation, the patient was satisfied and showed excellent clinical result. Preoperative sagittal T2-weighted MRI (a) showed the sagittal configuration of OLF (round type). Preoperative axial CT scan (b) showed the axial configurations of OLF (bilateral type). Postoperative axial (c), sagittal (d) and coronal (e) CT scans showed decompression of the spinal cord at T9-T11. 
Table 3 Correlations of postoperative RR and various factors by means of univariate statistics $(n=85)$

\begin{tabular}{|c|c|c|c|c|c|c|}
\hline Factors & Classification & No. & Mean \pm s.d. & Range & $t$ & $P$ \\
\hline \multirow[t]{2}{*}{ Sex } & M & 54 & $62.94 \pm 21.98$ & $20.00-100.00$ & 0.01 & 0.9922 \\
\hline & $\mathrm{F}$ & 31 & $62.89 \pm 24.80$ & $0.00-100.00$ & & \\
\hline \multirow[t]{3}{*}{ Age at surgery, (years) ${ }^{a}$} & $<60$ & 46 & $67.75 \pm 23.74$ & $0.00-100.00$ & 4.94 & 0.0094 \\
\hline & $60-70$ & 28 & $62.14 \pm 18.84$ & $22.22-100.00$ & & \\
\hline & $>70$ & 11 & $44.70 \pm 20.88$ & 20.00-80.00 & & \\
\hline \multirow[t]{2}{*}{$\mathrm{BMI},\left(\mathrm{kg} \mathrm{m}^{-2}\right)$} & $<25$ & 56 & $61.28 \pm 22.55$ & $0.00-100.00$ & 0.91 & 0.3632 \\
\hline & $\geqslant 25$ & 29 & $66.08 \pm 23.65$ & $20.00-100.00$ & & \\
\hline \multirow[t]{2}{*}{ Current smoking } & Yes & 18 & $54.68 \pm 24.93$ & $0.00-100.00$ & 1.74 & 0.0857 \\
\hline & No & 67 & $65.13 \pm 22.00$ & $11.11-100.00$ & & \\
\hline \multirow[t]{2}{*}{ Alcohol } & Yes & 13 & $66.23 \pm 21.58$ & $30.00-100.00$ & 0.56 & 0.5741 \\
\hline & No & 72 & $62.32 \pm 23.23$ & $0.00-100.00$ & & \\
\hline \multirow[t]{2}{*}{ Diabetes mellitus } & Yes & 9 & $55.56 \pm 33.42$ & $0.00-100.00$ & 1.02 & 0.3106 \\
\hline & No & 76 & $63.79 \pm 21.47$ & $11.11-100.00$ & & \\
\hline \multirow[t]{3}{*}{ Preoperative duration of symptoms, (months) } & $\leqslant 6$ & 25 & $81.77 \pm 14.00$ & $57.14-100.00$ & 37.60 & $<0.0001$ \\
\hline & $6-12$ & 15 & $75.66 \pm 13.12$ & $50.00-100.00$ & & \\
\hline & $\geqslant 12$ & 45 & $48.20 \pm 18.99$ & $0.00-83.33$ & & \\
\hline \multirow[t]{3}{*}{ OLF levela } & Upper thoracic & 22 & $60.68 \pm 22.23$ & $11.11-100.00$ & 6.67 & 0.0021 \\
\hline & Middle thoracic & 19 & $48.83 \pm 22.26$ & $20.00-100.00$ & & \\
\hline & Lower thoracic & 44 & $70.12 \pm 20.80$ & $0.00-100.00$ & & \\
\hline \multirow[t]{2}{*}{ Number of OLF levels } & 1 & 44 & $63.07 \pm 19.18$ & $11.11-100.00$ & 0.06 & 0.9487 \\
\hline & $\geqslant 2$ & 41 & $62.75 \pm 26.57$ & $0.00-100.00$ & & \\
\hline \multirow[t]{3}{*}{ Type of OLF (axial configurations) } & Unilateral & 19 & $74.09 \pm 19.64$ & $28.57-100.00$ & 5.62 & 0.0051 \\
\hline & Bilateral & 27 & $66.74 \pm 18.85$ & $37.50-100.00$ & & \\
\hline & Bridged & 39 & $54.83 \pm 24.36$ & $0.00-100.00$ & & \\
\hline \multirow[t]{2}{*}{ Type of OLF (sagittal configurations) } & Beak & 32 & $62.36 \pm 22.29$ & $11.11-100.00$ & 0.17 & 0.8633 \\
\hline & Round & 53 & $63.25 \pm 23.47$ & $0.00-100.00$ & & \\
\hline \multirow[t]{2}{*}{ DO } & Yes & 21 & $56.83 \pm 25.02$ & $22.22-100.00$ & 1.41 & 0.1617 \\
\hline & No & 64 & $64.92 \pm 22.00$ & $0.00-100.00$ & & \\
\hline \multirow[t]{2}{*}{ Aided by fusion with instrumentation } & Yes & 28 & $67.67 \pm 22.88$ & $20.00-100.00$ & 1.35 & 0.1814 \\
\hline & No & 57 & $60.58 \pm 22.75$ & $0.00-100.00$ & & \\
\hline \multirow[t]{2}{*}{ Intramedullary signal change on $\mathrm{T} 2 \mathrm{WI}{ }^{\mathrm{a}}$} & Yes & 18 & $43.39 \pm 26.08$ & $0.00-100.00$ & 4.52 & $<0.0001$ \\
\hline & No & 67 & $68.16 \pm 18.99$ & $11.11-100.00$ & & \\
\hline \multirow[t]{3}{*}{ Preoperative severity of myelopathy (JOA score) ${ }^{a}$} & $\geqslant 7$ & 32 & $44.93 \pm 17.71$ & $11.11-87.50$ & 29.39 & $<0.0001$ \\
\hline & $4-6$ & 43 & $70.97 \pm 17.32$ & $0.00-100.00$ & & \\
\hline & $\leqslant 3$ & 10 & $85.83 \pm 19.27$ & $50.00-100.00$ & & \\
\hline
\end{tabular}

Abbreviations: BMI, body mass index; DO, dural ossification; JOA, Japanese Orthopaedic Association; OLF, ossification of the ligamentum flavum; RR, recovery rate.

astatistically significant difference $(P<0.05)$.

regression analysis showed that the OLF level (middle thoracic), preoperative duration of symptoms, intramedullary signal change on T2WI and preoperative severity of myelopathy were important predictors of surgical outcome $(P<0.05$, Table 4$)$.

\section{DISCUSSION}

Epidemiology and pathogenesis

Thoracic OLF is rare and usually asymptomatic. The disease usually progresses insidiously over a long period of time and can eventually cause myeloradiculopathy and pain. Analysis of previously published epidemiological data revealed that the mean age of thoracic OLF patients ranged from 50 to 60 years and most required surgical treatment. ${ }^{17,18,21}$ Another large-scale epidemiological study on OLF in patients who presented with chest symptoms and underwent multidetector CT examination showed that the prevalence rate of OLF was much higher, at $63.9 \%$, than in previous reports. ${ }^{18}$ The process of OLF occurred earlier than was previously thought and was even found in 10-19-year-old individuals. The prevalence peaked in the 50-60 years age group, and tended increase with increasing age. Our data show that $54.2 \%$ of patients were diagnosed with symptomatic thoracic OLF at less than 60 years of age, followed by those of $60-70$ years $(32.9 \%)$ and more than 70 years of age $(12.9 \%)$. We also found that the prevalence of OLF in men was higher than in women at most segments, which was in line with most of the literature. ${ }^{12,15,18,36}$ This finding may be due to heavier physical activity in men, which causes heavier stress on the ligamentum flavum. However, in some studies, the prevalence rates were reported to be higher in women than in men. ${ }^{4,17,20}$

OLF is not only an isolated form of spinal column ossification but also occurs in association with diffuse idiopathic skeletal hyperostosis, ankylosing spondylitis and metabolic diseases such as Paget disease, hypoparathyroidism and X-linked hypophosphatemia. ${ }^{25,34,37}$ Although it has been 90 years since the first description of OLF, very little is known about the pathophysiology of OLF. Currently, several studies have described the possible roles of mechanical/traumatic, ${ }^{14,38-41}$ metabolic, ${ }^{42,43}$ chronic degenerative, ${ }^{44,45}$ biological/hereditary, ${ }^{46,47}$ environmental $^{48,49}$ and genetic factors ${ }^{50-53}$ in the development and progression of OLF.

In the literature, the lower thoracic spine (T10-T12) is the most frequently affected segment whereas the middle thoracic vertebrae (T5-T8) are rarely affected within the thoracic spine. ${ }^{15,18,34,54,55}$ In our study, we also found similar results. In addition, it has been reported 
Table 4 Risk factors associated with surgical outcomes by means of multiple linear regression $(n=85)$

\begin{tabular}{lcrr}
\hline Risk factors & Parameter estimate & Standard error & $t$ \\
\hline Age at surgery & -0.20334 & 0.20857 & -0.97 \\
Intramedullary signal change on T2WI & -14.18303 & 4.19263 & 0.3331 \\
OLF level (middle thoracic) & -7.77402 & 3.63471 & -3.38 \\
Type of OLF (axial classification) $_{\text {Preoperative duration of symptoms }}^{\text {a }}$ & 4.19031 & -2.14 & 0.0011 \\
Preoperative severity of myelopathy $^{\mathrm{a}}$ & -8.80622 & 2.01387 & 0.0355 \\
\hline
\end{tabular}

Abbreviation: OLF, ossification of the ligamentum flavum.

a Statistically significant difference $(P<0.05)$.

that the location of OLF is less vulnerable in mobile segments such as the cervical and lumbar vertebra than in the thoracic vertebrae. $^{26,30,40,55,56}$ This phenomenon gives us insight about the pathogenetic mechanism of OLF. On the basis of the literature review, we hypothesized that biomechanical and anatomical factors might have a key role in thoracic OLF progression. The lumbar and cervical regions are much more flexible than the thoracic spine in terms of flexion/extension and lateral bending. The unstable mechanical environment is not suitable for osteogenic differentiation of ligamentum flavum cells. As the range of motion becomes more restricted in thoracic spine relative to the cervical or lumbar spine, the length of the elastic fibers in the ligamentum flavum is kept in a narrow range during dynamic motion, and calcification may occur more frequently in this relatively stable environment. This hypothesis was histologically supported by the OLF found in the hypertrophic ligament flavum with fibrocartilage proliferation, which was thought to be a result of mechanical stress because of tensile force. ${ }^{30}$ As the lower thoracic spine is a transitional area in spinal curvature, the elastic fibers in ligamentum flavum may be relaxed and thickened relatively. In addition to the anatomical difference relating to mechanical stress involving constraints on the articular processes during segmental motion, this difference may also be attributed to increased instability in lower thoracic spine. ${ }^{41,55,57}$ Compared with the middle thoracic spine, it seems to be more particularly easy to make degenerative processes on the lower thoracic spine owing to the high tensile force present on the posterior column. ${ }^{22,55}$ Maigne et al. ${ }^{55}$ reported that OLF occurred most frequently at the lower thoracic spine especially at the thoracolumbar junction, and its appearance correlated with a unique orientation of the facet joints that generated increased rotatory instability and micromotion.

\section{Clinical and radiographic characteristics of thoracic OLF}

Ligamentum flavum has two portions, the interlaminar and the capsular ones. ${ }^{58}$ Ossification usually begins in the capsular portion and spreads to the laminar portion. ${ }^{11}$ OLF compresses the spinal cord or root from the posterolateral side and causes symptoms. Most of the thoracic OLF patients showed the typical features of TM: that is, sensory and motor deficits in the trunk and lower extremities, sphincter disturbance and exaggerated tendon reflexes. OLF is most often asymptomatic but may present as two different symptoms. The first involves chronic spinal cord compression over a long period of time and presents with unsteady gait, difficulty with balance and climbing stairs, with or without unilateral/bilateral neurogenic claudication. In the second one, OLF may present as acute myelopathy after minor trauma. There is a sudden compromise in an asymptomatic, but narrowed, spinal canal by hematoma and edema, with or without bony/soft tissue impingement secondary to the trauma. The motor and sensory deficits are usually more severe than the first one and recovery is usually poor. To improve the clinical outcome of thoracic OLF, early diagnosis in patients with a less severe pathologic lesion would be critical. In this view, meticulous physical examination might help to make an accurate diagnosis for thoracic OLF patients.

Before the early 1990s, when MRI was not commonly used for neurological diagnosis, CT was considered the best diagnostic tool to detect thoracic OLF. ${ }^{23,26,30,36}$ OLF can be confirmed to mainly present in the foraminal region on $\mathrm{CT}$, which not only provide an accurate assessment of the contour of the ossification but also show the ossification of dura mater and the size of the spinal canal. Pascal-Moussellard et al. ${ }^{28}$ reported sagittal reconstructions of CT that are helpful for distinguishing OLF from calcification of the ligamenta flava, which is the only differential diagnosis of OLF. Myelography combined with CT can show spinal cord compression but is, at present, commonly replaced by MRI as the modality of choice for neural elements and the cord. As OLF tends to occur in multiple locations, MRI should be used to show the distribution of OLF to prevent missing affected levels. Additionally, MRI is able to detect coexisting spinal lesions in the cervical and/or lumbar spine, which are not uncommon in thoracic OLF patients. A high-intensity signal in the spinal cord on T2-weighted MRI is thought to indicate edema, demyelination, myelomalacia, cavitation or necrosis and related to the severity of the myelopathy. ${ }^{56,59-61}$ However, MRI alone is insufficient for the diagnosis of OLF because a low-intensity signal on T1- and T2-weighted sequences is indistinguishable from that corresponding to a hypertrophic ligamentum flavum. Consequently, as we have performed in our study, preoperative whole-spine MRI combined with CT are recommended to establish an accurate diagnosis and to determine the extent of surgical procedure.

\section{Surgical treatment and complication of thoracic OLF}

Conservative treatments have proven to be ineffective for symptomatic patients of thoracic OLF. ${ }^{26,28,57}$ Surgery is the only treatment that can adequately address the significant compression of neurologic structures caused by OLF. ${ }^{1,29,62-64}$ The goal of surgical intervention is to excise the ossified segments and provide sufficient decompression. Posterior decompression is the most commonly reported surgical method, and total laminectomy is the most commonly used means of achieving such decompression. The range of decompression used differs in various reports, ${ }^{29,30,32,64}$ and most researchers consider that the range of decompression should encompass the medial one-third to one-half of the facet joint and one or possibly two laminae superior and inferior to the diseased segment. ${ }^{15,26}$ All patients in our study received posterior decompressive laminectomy. A statistically significant improvement in the JOA score was obtained at the 4-year followup examination. However, most of the recoveries were incomplete, with a mean of $63.0 \%$, which was similar to those in prior reports. ${ }^{4,15,19,30,56}$ 
Use of spinal fusion to treat TM caused by OLF is controversial. Kyphotic spinal deformity after thoracic laminectomy may cause neurologic deterioration. To minimize the risk of spinal instability or kyphotic deformity, spinal fusion with internal instrumentation was partially performed for patients with multilevel OLF mainly at the cervicothoracic junction and thoracolumbar junction. In our study, posterior laminectomy combined with spinal fusion with instrumentation was performed in 28 patients (32.9\%). No obvious instability or kyphotic deformity was seen at the final follow-up. However, the essentiality of this procedure should be evaluated in further comparative studies.

Some authors have recommended laminoplasty for the treatment of OLF, because of late neurological deterioration due to the recurrence of OLF at the same site or increased kyphotic deformity of the spine. ${ }^{30,65}$ However, laminoplasty is not suitable for severe OLF because they will only achieve limited decompression and because the possibility of reclosure exists. Laminoplasty, for example, merely expands the volume of the spinal canal and does not remove the ossified ligamentum flavum. Residual compression may remain if the size of the ossified lesion is large. Furthermore, lamina treated with laminoplasty may return to the preoperative position, the surgical procedure is relatively complicated and the long-term effect is less reliable than that of the surgical technique reported here. ${ }^{56,65}$

As we all know, each surgical procedure has its own complications. Dural tears and CSF leakage are the most common complications of thoracic OLF surgery and can lead to CSF pseudocyst, respiratory obstruction, wound dehiscence and meningitis. ${ }^{66-68}$ Because dural adhesion and DO are more common in thoracic OLF than in cervical or lumbar spine, the incidence of CSF leakage in OLF patients may be higher. ${ }^{56,68-70}$ Miyakoshi et al. ${ }^{56}$ reported that dural adhesion was observed in $62 \%$ of the 34 patients with OLF, and found that dural adhesion was frequently observed in larger types of OLF. Aizawa et al. ${ }^{11}$ reported that 9 of 72 patients with OLF had dual tears during surgery and 8 of them had DO. Ben Hamouda et al. ${ }^{26}$ reported the incidence of dural tears as being $22 \%(4 / 18)$. In our series, the incidence of DO, dural tears and CSF leakage was $24.7 \%, 20 \%$ and $10.6 \%$, respectively. Among the nine patients in our study with CSF leakage, seven had DO, for an incidence of $77.8 \%$; therefore, DO was characterized as the main reason of CSF leakage in patients with OLF. In addition, compared with other thoracic pathologies that do not cause DO, the incidence of dural tears and CSF leakage with thoracic laminectomies in our study is relatively high. ${ }^{71,72}$ This would strengthen the statement that dural tears and CSF leakage are associated with DO and complicates surgical repair of the disorder. The intraoperative manipulation should be gentle to avoid dural tears as much as possible, and once a dura mater tear is noticed, immediate repair should be carried out. ${ }^{56,68,70}$ Eight cases underwent dura mater repair and no CSF leakage happened after the operation, and the surgical effect was satisfactory. Although the procedure and success of intraoperative repair is important, comprehensive treatments after operation should not be ignored. In our study, we kept the patient with dural tears in a prone or lateral position. These positions played an important role in the process of dural healing because they reduced hydrostatic pressure on the repaired dura and reduced the caustic effect of CSF, providing an environment amenable to the healing process. In our study, CSF leakage stopped after 5-7 days in all nine cases. CSF pseudocyst was a common complication related to CSF leakage. Two patients developed CSF pseudocyst during the follow-up in our series, both of which were cured by repeated ultrasound-guided puncture and aspiration with strict aseptic measures. CSF leakage did not result in any neurologic degradation but was associated with patient discomfort, which improved gradually within the first postoperative month. Therefore, accurate preoperative identification of the DO, active preparation for the repair of dura mater and comprehensive treatments after operation can make the patient recover more quickly and completely. Some research showed that, if OLF encroached dura mater, we can select 'floating method' which is a microscopic technique for decompression to avoid CSF leakage. ${ }^{73,74}$

Another serious surgical complication in thoracic OLF surgery is spinal cord injury. ${ }^{62,75,76}$ Several procedures were followed with the aim of minimizing the risk of spinal cord injury. To avoid injury to the blood supply to the spinal cord, the microcirculation around the intervertebral foramen should be protected when ligating the vertebral segmental vessels. The Adamkiewicz artery should be carefully protected. This artery lies on the left side at T7-L4 in about $80 \%$ of cases and usually supplies the nutrient arteries to the spinal cord at T9-L1. 15,57,62,67,77 Injury to the Adamkiewicz artery may be disastrous. Intraoperative evoked-potential monitoring can reduce the risk of spinal cord injury. In our study, evoked-potential monitoring was utilized as an intraoperative monitoring tool for all the cases, iatrogenic spinal cord injury was effectively avoided. Besides, a highspeed air drill was used for all patients in our study during the decompression process, and, after sufficiently dissociating the bilateral borders and the cranial and caudal ends over the selected decompression area, the compressing materials were excised at once to avoid the repeated irritation to the spinal cord caused by a sequential excision process. However, there were four patients suffering from late postoperative neurologic deterioration or persistent aggravation of paralysis in our series. We think that potential etiologies may include ischemia-reperfusion injury, microthrombi and altered perfusion due to internal recoil of spinal cord architecture following decompression.

Postoperative epidural hematomas are another complication, usually on the day of surgery, and can cause postoperative spinal cord compression and induce symptom aggravation. ${ }^{32}$ Their occurrence is correlated with incomplete intraoperative hemostasis, blocked drainage tubes or coagulopathy. No postoperative epidural hematoma occurred in the present study. This lack of epidural hematomas was probably due to the intraoperative hemostasis and postoperative draining used in the current study. Hematomas in the vertebral canal can injure the spinal cord with catastrophic consequences if it is not treated urgently. If neural dysfunction gradually increases after the operation, the possibility of epidural hematoma should be considered and, if high doses of methylprednisolone do not improve the symptoms, surgical exploration should be carried out after a short period of observation.

\section{Prognostic factors for thoracic OLF}

Several authors reported that some factors might affect the surgical outcome which included preoperative neurological status, duration of preoperative symptoms, CT findings, intramedullary signal change on T2WI, age, sex, number of levels involved, and type of OLF and so on. ${ }^{13,19,20,22,33,34,56}$ Preoperative severity of myelopathy was considered as the most important predictor of the postoperative outcome. ${ }^{19,20,22,56}$ In accordance with this finding, our research confirmed that preoperative severity of myelopathy was the most important predictor of the highest postoperative JOA score and the lowest percentage $\mathrm{RR}$ in multiple linear regression analyses. In addition, the OLF level (middle thoracic), preoperative duration of symptoms and intramedullary signal change on T2WI were also confirmed and significantly correlated with the surgical outcome by multiple regression analysis. Meanwhile, our research revealed that sex, age at surgery, body mass index, current smoking, alcohol, 
diabetes mellitus, number of levels involved, sagittal configurations (beak or round), axial configurations (unilateral, bilateral or bridged), DO and aided by fusion with instrumentation were not significantly related to the surgical outcome.

\section{Limitations}

A limitation of this study was that it was a retrospective unrandomized case-control study, and the numbers of patients in this study were relatively small. The mean 49.2 months follow-up duration in this study was too short to evaluate the efficacy of posterior decompressive laminectomy and resection of the OLF in treatment of TM caused by OLF. In addition, patients of thoracic OLF are often associated with the coexisting spinal disorders, such as ossification of posterior longitudinal ligament, disc herniation, canal stenosis or OLF at other spinal levels, were reported to make the surgical decision more complicated and the surgical outcome more unpredictable. However, the subjects were excluded in our study. Further large-scale prospective investigations on the predictive factors for poor surgical outcome in thoracic OLF surgery through long-term follow-up period will be necessary in the future.

\section{CONCLUSIONS}

Thoracic OLF is a relatively common disease that produces myelopathy in the thoracic area. The thoracic OLF has the problems of relatively high surgical risk and unpredictable surgical outcome. On the basis of the results of this study, we think that biomechanical and anatomical factors may have a key role in thoracic OLF progression. Posterior decompressive laminectomy and resection of the OLF can be considered an effective, reliable and safe alternative procedure in the treatment of TM caused by OLF. The OLF level, preoperative duration of symptoms, intramedullary signal change on T2WI and preoperative severity of myelopathy were confirmed and significantly correlated with the surgical outcome.

\section{DATA ARCHIVING}

There were no data to deposit.

\section{CONFLICT OF INTEREST}

The authors declare no conflict of interest.

1 Akhaddar A, Mansouri A, Zrara I, Gazzaz M, Maftah M, Mostarchid B et al. Thoracic spinal cord compression by ligamentum flavum ossifications. Joint Bone Spine 2002; 69: 319-323.

2 Barnett GH, Hardy RW Jr, Little JR, Bay JW, Sypert GW. Thoracic spinal canal stenosis. J Neurosurg 1987; 66: 338-344.

3 Wang W, Kong L, Zhao H, Dong R, Zhou J, Lu Y. Thoracic myelopathy caused by ossification of ligamentum flavum of which fluorosis as an etiology factor. J Orthop Surg Res 2007; 2: 6.

4 Li M, Wang Z, Du J, Luo Z, Wang Z. Thoracic myelopathy caused by ossification of the ligamentum flavum: a retrospective study in Chinese patients. J Spinal Disord Tech 2013; 26: E35-E40.

5 Furtado SV, Dadlani R, Ghosal N, Rao AS. Solitary thoracic vertebral body cysticercosis presenting with progressive compressive myelopathy. J Neurosurg Spine 2013; 18: 394-397.

6 Teufack S, Campbell P, Sharma P, Lachman T, Kenyon L, Harrop J et al. Thoracic myelopathy due to an intramedullary herniated nucleus pulposus: first case report and review of the literature. Neurosurgery 2012; 71: E199-E202.

7 Amato V, Giannachi L, Irace C, Corona C. Thoracic spinal stenosis and myelopathy: report of two rare cases and review of the literature. J Neurosurg Sci 2012; 56 373-378.

8 Cornips EM, Janssen ML, Beuls EA. Thoracic disc herniation and acute myelopathy: clinical presentation, neuroimaging findings, surgical considerations, and outcome. J Neurosurg Spine 2011; 14: 520-528.

9 Yamazaki M, Mochizuki M, Ikeda Y, Sodeyama T, Okawa A, Koda M et al. Clinical results of surgery for thoracic myelopathy caused by ossification of the posterior longitudinal ligament: operative indication of posterior decompression with instrumented fusion. Spine (Phila Pa 1976) 2006; 31: 1452-1460.

10 Stollman A, Pinto R, Benjamin V, Kricheff I. Radiologic imaging of symptomatic ligamentum flavum thickening with and without ossification. AJNR Am J Neuroradiol 1987; 8: 991-994.

11 Aizawa T, Sato T, Sasaki H, Kusakabe T, Morozumi N, Kokubun S. Thoracic myelopathy caused by ossification of the ligamentum flavum: clinical features and surgical results in the Japanese population. J Neurosurg Spine 2006; 5: 514-519.

12 Mori K, Kasahara T, Mimura T, Nishizawa K, Murakami Y, Matsusue Y et al. Prevalence, distribution, and morphology of thoracic ossification of the yellow ligament in Japanese: results of CT-based cross-sectional study. Spine (Phila Pa 1976) 2013; 38: E1216-E1222.

13 Kawaguchi Y, Yasuda T, Seki S, Nakano M, Kanamori M, Sumi S et al. Variables affecting postsurgical prognosis of thoracic myelopathy caused by ossification of the ligamentum flavum. Spine J 2013; 13: 1095-1107.

14 Kaneyama S, Doita M, Nishida K, Shimomura T, Maeno K, Tamura Y et al. Thoracic myelopathy due to ossification of the yellow ligament in young baseball pitchers. J Spinal Disord Tech 2008; 21: 68-71.

15 Yu S, Wu D, Li F, Hou T. Surgical results and prognostic factors for thoracic myelopathy caused by ossification of ligamentum flavum: posterior surgery by laminectomy. Acta Neurochir 2013; 155: 1169-1177.

16 Gao R, Yuan W, Yang L, Shi G, Jia L. Clinical features and surgical outcomes of patients with thoracic myelopathy caused by multilevel ossification of the ligamentum flavum. Spine J 2013; 13: 1032-1038.

17 Guo JJ, Luk KD, Karppinen J, Yang H, Cheung KM. Prevalence, distribution, and morphology of ossification of the ligamentum flavum: a population study of one thousand seven hundred thirty-six magnetic resonance imaging scans. Spine (Phila Pa 1976) 2010; 35: 51-56.

18 Lang N, Yuan HS, Wang HL, Liao J, Li M, Guo FX et al. Epidemiological survey of ossification of the ligamentum flavum in thoracic spine: CT imaging observation of 993 cases. Eur Spine J 2013; 22: 857-862.

19 He S, Hussain N, Li S, Hou T. Clinical and prognostic analysis of ossified ligamentum flavum in a Chinese population. J Neurosurg Spine 2005; 3: 348-354.

20 Kang KC, Lee CS, Shin SK, Park SJ, Chung CH, Chung SS. Ossification of the ligamentum flavum of the thoracic spine in the Korean population. JNeurosurg Spine 2011; 14: 513-519.

21 Park BC, Min WK, Oh CW, Jeon IH, Kim SY, Kyung HS et al. Surgical outcome of thoracic myelopathy secondary to ossification of ligamentum flavum. Joint Bone Spine 2007; 74: 600-605.

22 Hur H, Lee JK, Lee JH, Kim JH, Kim SH. Thoracic myelopathy caused by ossification of the ligamentum flavum. J Korean Neurosurg Soc 2009; 46: 189-194.

23 Omojola MF, Cardoso ER, Fox AJ, Drake CG, Durward QJ. Thoracic myelopathy secondary to ossified ligamentum flavum. J Neurosurg 1982; 56: 448-450.

24 Shiraishi T, Crock HV, Lewis P. Thoracic myelopathy due to isolated ossification of the ligamentum flavum. J Bone Joint Surg Br 1995; 77: 131-133.

25 Epstein NE. Ossification of the yellow ligament and spondylosis and/or ossification of the posterior longitudinal ligament of the thoracic and lumbar spine. J Spinal Disord 1999; 12: 250-256.

26 Ben Hamouda K, Jemel H, Haouet S, Khaldi M. Thoracic myelopathy caused by ossification of the ligamentum flavum: a report of 18 cases. J Neurosurg 2003; 99: 157-161.

27 Pascal-Mousselard H, Smadja D, Cabre P, Raynaud M, Catonne Y. Ossification of the ligamenta flava with severe myelopathy in a black patient. A case report. Spine (Phila Pa 1976) 1998; 23: 1607-1608.

28 Pascal-Moussellard H, Cabre P, Smadja D, Catonne Y. Symptomatic ossification of the ligamentum flavum: a clinical series from the French Antilles. Spine (Phila Pa 1976) 2005; 30: E400-E405.

29 Nishiura I, Isozumi T, Nishihara K, Handa H, Koyama T. Surgical approach to ossification of the thoracic yellow ligament. Surg Neurol 1999; 51: 368-372.

30 Okada K, Oka S, Tohge K, Ono K, Yonenobu K, Hosoya T. Thoracic myelopathy caused by ossification of the ligamentum flavum. Clinicopathologic study and surgical treatment. Spine (Phila Pa 1976) 1991; 16: 280-287.

31 Tomita K. Total decompression of the spinal cord for combined ossification of posterior longitudinal ligament and yellow ligament in the thoracic spine. Arch Orthop Trauma Surg 1990; 109: 57-62.

32 Tomita K, Kawahara N, Baba H, Kikuchi Y, Nishimura H. Circumspinal decompression for thoracic myelopathy due to combined ossification of the posterior longitudinal ligament and ligamentum flavum. Spine (Phila Pa 1976) 1990; 15: 1114-1120.

33 Kuh SU, Kim YS, Cho YE, Jin BH, Kim KS, Yoon YS et al. Contributing factors affecting the prognosis surgical outcome for thoracic OLF. Eur Spine J 2006; 15: 485-491.

34 Inamasu J, Guiot BH. A review of factors predictive of surgical outcome for ossification of the ligamentum flavum of the thoracic spine. J Neurosurg Spine 2006; 5: 133-139.

35 Hirabayashi K, Miyakawa J, Satomi K, Maruyama T, Wakano K. Operative results and postoperative progression of ossification among patients with ossification of cervical posterior longitudinal ligament. Spine (Phila Pa 1976) 1981; 6: 354-364.

36 Miyasaka K, Kaneda K, Sato S, Iwasaki Y, Abe S, Takei H et al. Myelopathy due to ossification or calcification of the ligamentum flavum: radiologic and histologic evaluations. AJNR Am J Neuroradiol 1983; 4: 629-632.

$37 \mathrm{Kim}$ TJ, Kim TH, Jun JB, Joo KB, Uhm WS. Prevalence of ossification of posterior longitudinal ligament in patients with ankylosing spondylitis. J Rheumatol 2007; 34: 2460-2462.

$38 \mathrm{Li} \mathrm{F}$, Chen Q, Xu K. Surgical treatment of 40 patients with thoracic ossification of the ligamentum flavum. J Neurosurg Spine 2006; 4: 191-197. 
39 Tsukamoto N, Maeda T, Miura H, Jingushi S, Hosokawa A, Harimaya K et al. Repetitive tensile stress to rat caudal vertebrae inducing cartilage formation in the spinal ligaments: a possible role of mechanical stress in the development of ossification of the spinal ligaments. J Neurosurg Spine 2006; 5: 234-242.

40 Liao CC, Chen TY, Jung SM, Chen LR. Surgical experience with symptomatic thoracic ossification of the ligamentum flavum. J Neurosurg Spine 2005; 2: 34-39.

41 Chen J, Wang X, Wang C, Yuan W. Rotational stress: role in development of ossification of posterior longitudinal ligament and ligamentum flavum. Med Hypotheses 2011; 76: 73-76.

42 Matsui H, Katoh Y, Tsuji H. Untreated hypophosphatemic vitamin D-resistant rickets with symptomatic ossification of the ligamentum flavum. J Spinal Disord 1991; 4: 110-113.

43 Vera CL, Cure JK, Naso WB, Gelven PL, Worsham F, Roof BF et al. Paraplegia due to ossification of ligamenta flava in X-linked hypophosphatemia. A case report. Spine (Phila Pa 1976) 1997; 22: 710-715.

44 Sharma RR, Mahapatra A, Pawar SJ, Sousa J, Lad SD, Athale SD. Spinal cord and cauda equina compression in 'DISH. Neurol India 2001; 49: 148-152.

45 Miyazawa N, Akiyama I. Ossification of the ligamentum flavum of the cervical spine. J Neurosurg Sci 2007; 51: 139-144.

46 Kosaka T, Imakiire A, Mizuno F, Yamamoto K. Activation of nuclear factor kappaB at the onset of ossification of the spinal ligaments. J Orthop Sci 2000; 5: 572-578.

47 Yayama T, Uchida K, Kobayashi S, Kokubo Y, Sato R, Nakajima H et al. Thoracic ossification of the human ligamentum flavum: histopathological and immunohistochemical findings around the ossified lesion. J Neurosurg Spine 2007; 7: 184-193.

48 Mobbs RJ, Dvorak M. Ossification of the ligamentum flavum: diet and genetics. J Clin Neurosci 2007; 14: 703-705.

49 Muthukumar N. Ossification of the ligamentum flavum as a result of fluorosis causing myelopathy: report of two cases. Neurosurgery 2005; 56: E622 discussion E622.

50 Liu Y, Zhao Y, Chen Y, Shi G, Yuan W. RUNX2 polymorphisms associated with OPLL and OLF in the Han population. Clin Orthop Relat Res 2010; 468: 3333-3341.

51 Kong Q, Ma X, Li F, Guo Z, Qi Q, Li W et al. COL6A1 polymorphisms associated with ossification of the ligamentum flavum and ossification of the posterior longitudinal ligament. Spine (Phila Pa 1976) 2007; 32: 2834-2838.

52 Uchida K, Yayama T, Cai HX, Nakajima H, Sugita D, Guerrero AR et al. Ossification process involving the human thoracic ligamentum flavum: role of transcription factors. Arthritis Res Ther 2011; 13: R144.

53 Cai HX, Yayama T, Uchida K, Nakajima H, Sugita D, Guerrero AR et al. Cyclic tensile strain facilitates the ossification of ligamentum flavum through beta-catenin signaling pathway: in vitro analysis. Spine (Phila Pa 1976) 2012; 37: E639-E646.

54 Ando K, Imagama S, Ito Z, Hirano K, Muramoto A, Kato F et al. Predictive factors for a poor surgical outcome with thoracic ossification of the ligamentum flavum by multivariate analysis: a multicenter study. Spine (Phila Pa 1976) 2013; 38: E748-E754.

55 Maigne JY, Ayral X, Guerin-Surville H. Frequency and size of ossifications in the caudal attachments of the ligamentum flavum of the thoracic spine. Role of rotatory strains in their development. An anatomic study of 121 spines. Surg Radiol Anat 1992; 14: 119-124.

56 Miyakoshi N, Shimada Y, Suzuki T, Hongo M, Kasukawa Y, Okada K et al. Factors related to long-term outcome after decompressive surgery for ossification of the ligamentum flavum of the thoracic spine. J Neurosurg 2003; 99: 251-256.

57 Chang UK, Choe WJ, Chung CK, Kim HJ. Surgical treatment for thoracic spinal stenosis. Spinal Cord 2001; 39: 362-369.

58 Beamer YB, Garner JT, Shelden CH. Hypertrophied ligamentum flavum. Clinical and surgical significance. Arch Surg 1973; 106: 289-292.
59 Enomoto H, Kuwayama N, Katsumata T, Doi T. Ossification of the ligamentum flavum. A case report and its MRI finding. Neuroradiology 1988; 30: 571-573.

60 Yonenobu K, Ebara S, Fujiwara K, Yamashita K, Ono K, Yamamoto T et al. Thoracic myelopathy secondary to ossification of the spinal ligament. J Neurosurg 1987; 66: 511-518.

61 Xiong L, Zeng QY, Jinkins JR. CT and MRI characteristics of ossification of the ligamenta flava in the thoracic spine. Eur Radiol 2001; 11: 1798-1802.

$62 \mathrm{He} \mathrm{B}$, Yan L, Xu Z, Guo H, Liu T, Hao D. Treatment strategies for the surgical complications of thoracic spinal stenosis: a retrospective analysis of two hundred and eighty three cases. Int Orthop 2014; 38: 117-122.

63 van Oostenbrugge RJ, Herpers MJ, de Kruijk JR. Spinal cord compression caused by unusual location and extension of ossified ligamenta flava in a Caucasian male. A case report and literature review. Spine (Phila Pa 1976) 1999; 24: 486-488.

64 Jia LS, Chen XS, Zhou SY, Shao J, Zhu W. En bloc resection of lamina and ossified ligamentum flavum in the treatment of thoracic ossification of the ligamentum flavum. Neurosurgery 2010; 66: 1181-1186.

65 Shimamura T, Kato S, Toba T, Yamazaki K, Ehara S. Sagittal splitting laminoplasty for spinal canal enlargement for ossification of the spinal ligaments (OPLL and OLF). Semin Musculoskelet Radiol 2001; 5: 203-206.

66 Khan MH, Rihn J, Steele G, Davis R, Donaldson WF 3rd, Kang JD et al. Postoperative management protocol for incidental dural tears during degenerative lumbar spine surgery: a review of 3,183 consecutive degenerative lumbar cases. Spine (Phila Pa 1976) 2006; 31: 2609-2613.

67 Takahata M, Ito M, Abumi K, Kotani Y, Sudo H, Minami A. Clinical results and complications of circumferential spinal cord decompression through a single posterior approach for thoracic myelopathy caused by ossification of posterior longitudinal ligament. Spine (Phila Pa 1976) 2008; 33: 1199-1208.

68 Sun X, Sun C, Liu X, Liu Z, Qi Q, Guo Z et al. The frequency and treatment of dural tears and cerebrospinal fluid leakage in 266 patients with thoracic myelopathy caused by ossification of the ligamentum flavum. Spine (Phila Pa 1976) 2012; 37: E702-E707.

69 Muthukumar N. Dural ossification in ossification of the ligamentum flavum: a preliminary report. Spine (Phila Pa 1976) 2009; 34: 2654-2661.

70 Sun $X Z$, Chen ZQ, Qi Q, Guo ZQ, Sun CG, Li WS et al. Diagnosis and treatment of ossification of the ligamentum flavum associated with dural ossification: clinical article. J Neurosurg Spine 2011; 15: 386-392.

71 Di Silvestre M, Parisini P, Lolli F, Bakaloudis G. Complications of thoracic pedicle screws in scoliosis treatment. Spine (Phila Pa 1976) 2007; 32: 1655-1661.

72 Hicks JM, Singla A, Shen FH, Arlet V. Complications of pedicle screw fixation in scoliosis surgery: a systematic review. Spine (Phila Pa 1976) 2010; 35: E465-E470.

73 Miyashita T, Ataka H, Tanno T. Spontaneous reduction of a floated ossification of the ligamentum flavum after posterior thoracic decompression (floating method); report of a case (abridged translation of a primary publication). Spine J 2013; 13: e7-e9.

74 Ikuta K, Tarukado K, Senba H, Kitamura T, Komiya N, Fukutoku Y et al. Decompression procedure using a microendoscopic technique for thoracic myelopathy caused by ossification of the ligamentum flavum. Minim Invasive Neurosurg 2011; 54: 271-273.

75 Kaneko K, Sakamoto S, Toyoda K, Kato Y, Taguchi T. False negative in spinal cord monitoring using spinal cord-evoked potentials following spinal cord stimulation during surgery for thoracic OPLL and OLF. J Spinal Disord Tech 2006; 19: 142-144.

76 Taher F, Lebl DR, Cammisa FP, Pinter DW, Sun DY, Girardi FP. Transient neurological deficit following midthoracic decompression for severe stenosis: a series of three cases. Eur Spine J 2013; 22: 2057-2061.

77 Epstein NE, Schwall G. Thoracic spinal stenosis: diagnostic and treatment challenges. J Spinal Disord 1994; 7: 259-269. 